\title{
Computer-Based Database System: Rapid Response for Rural Planning Agencies to Devise Transport Policies
}

\author{
Mir Aftab Hussain Talpur*, Imtiaz Ahmed Chandio, \\ Irfan Ahmed Memon and Taufiq Ahmed Qureshi \\ Department of City and Regional Planning, Mehran University of Engineering and \\ Technology, Jamshoro-76062, Sindh, Pakistan; aftab.talpur@faculty.muet.edu.pk
}

\begin{abstract}
The aim of this study is to develop the Computer-Based Database System (CBDS), which can entertain the data-related matters of rural planning agencies for effective policy formulation. Unavailability of data and its proper management are the pressing problems of rural planning agencies over the years, which are responsible for the delay execution of policy proposals in developing countries to some extend. Hence, CBDS was developed to manage rural data regarding various development sectors, but mostly physical and socioeconomic. Data can be easily retrieved with the help of this system, which can help in the formulation of relevant policies. Transportation policies can be formulated on time with the help of CBDS focusing accessibility problems. Transport accessibility can ease out the difficulties of rural-regional population in accessing amenities and credential services.
\end{abstract}

Keywords: Computer-Based Database System, Rural Planning Agencies, Accessibility Problems, Policy Formulation, Rural Sub-Regions, Transport Policies

\section{Introduction}

Transport sector supports socioeconomic flows between deprived regions and well-established commercial centers $^{1,2}$. Transportation flows are necessary for the development of rural areas, and considered as a lifeline for the rural inhabitants. However, these are always affected by the improper provision and lack of transportation services, particularly in the developing countries ${ }^{3-5}$. The rural population often had trouble in accessing their basic needs, which enhanced their difficulties and lower-down accessibility standard ${ }^{5,6}$. There are many reasons involved behind such phenomenon, including negligence of concerned governments, mismanagement, shortage of funds and most crucial absence of transport policy outlines ${ }^{7}$. Transport policies often developed by concerned planning agencies at a local level to curb the local transport issues. The local development authorities are responsible for the formulation of sub-regional policy proposals, including master plans, local plans or district plans for their entire regions ${ }^{8}$. In developing countries, rural planning agencies failed to formulate transport policy proposals in time. There could be many reasons for that, but this study deals with the data issues, these rural planning agencies are facing over the years. Henceforth, the focal points of this study are:

a) The development of a CBDS, which can assist local planning agencies in their data handling issues. It is expected that by overwhelming data issues, concerned planning authorities would be able to formulate policy plans, focusing rural inaccessibility issues.

b) Data concerns, because rural authorities were facing the problems with data management and its proper handling, which resulted the deferment in the development of regional transportation planning frameworks.

c) The availability of data and its management could help the concerned authorities in their policy making efficiently. According to the United Nations?, 
authentic transportation data are essential for providing efficient access to goods and services. Data are significant for the development and planning of physical and socioeconomic infrastructure, like rural roads, agriculture tracks, walkways, bicycle paths, primary health care facilities, basic education and their efficient connectivity. Further, good quality transport and socioeconomic data are essential for the development of rural regions and their sustainability. The data need to be retrieved, displayed and analyzed promptly, as concerned authorities can make relevant policy plans. Therefore, planning authorities needed a tool or a system, which can facilitate in processing the data in time and assist in the decision-making process. Thus, in this study, data are also taken as a measure of accessibility, because if data would not be available, no policy plans or proposals could be made to resolve the rural accessibility problems.

d) The planning agencies are responsible for the planning and development of their concerned areas. Nonetheless, these authorities in developing countries struggled to meet with the ever-increasing demands of their people and failed to deliver on time. There are many issues involved behind, such as shortages of funding, professionals and systematic tools or automated systems, which can store the data for these rural authorities. The important data always needed for policy formulations and development proposals. However, in most of the developing countries, rural planning agencies rely on the paper formatting data, which could not be retrieved easily when needed. At the same time, these paper format data would be of no use after a certain period, as these deteriorated with the passage of time. The concerned authorities intended to prepare plans, targeting traffic congestion problems in urban areas, and solve the problems of transportation unavailability (inaccessibility) within rural regions.

CBDS and other systems of such type ${ }^{10,11}$ can be prolific and bona fide in managing the data for local planning agencies. The development of CBDS could embark the role of planning authorities in providing solutions to the problems of the local population, including inaccessibility. This research could positively decipher the issue of data availability for development authorities, as these could foster their decision-making process. The assessments can be made and implemented in the form of transportation policy plans. Transportation policies, when implemented can resolve the problems of the rural population in their movement and easy retrieval of basic services. These sorts of plans can enhance the individual accessibility, as the local population can access their basic needs without any delays.

\section{Material and Methods}

Pakistan is a state of four provinces and a developing country, which is facing many physical and socioeconomic problems ${ }^{12}$. These problems included the higher growth rate of population, unemployment, unavailability of reliable transport policy ${ }^{13}$, a higher rate of ruralurban migration, lack of services and basic amenities, unavailability of proper infrastructure and poverty ${ }^{14,15}$. The province of Sindh was the second largest province of Pakistan amongst the four from a population point of view, i.e. 30.44 million $^{16}$ and having an area of about $140,914 \mathrm{~km}^{2}$ or $54407 \mathrm{mi}^{2}$. According to World Bank ${ }^{17}$, the total land area of Pakistan was about $770,880 \mathrm{~km}^{2}$.

There are varieties of data collection and survey techniques available to retrieve data ${ }^{18}$. To complete the objective of study, i.e. development of the computerbased database system, data were taken from the "Hyderabad Master Plan, 2001-2015". Hyderabad was the second largest region of Sindh province ${ }^{19}$, having a total area of about $300 \mathrm{~km}^{2}$.

\subsection{Master Plan}

Master plan principally is a written statement supplemented by any auxiliary diagrammatic illustrations and a design to introduce a major flexibility into a system ${ }^{20,21}$. This is a traditional method for representing a set of land-use allocations, and control measures in the form of a map. Usually, master plans are made for long-term planning, i.e. 15-30 years. Once the details of the master plan were finalized, comprehensive planning of the various sections was taken place and if found necessary, the proposals of the master plan reviewed periodically usually after every five years. However, the task of preparing the master plan for any city or town is complex and demands a high degree of skills.

\subsection{Demographic Trends}

The population of Hyderabad in a year 2000 was around 1,400,000; the second highest at provincial and considered 
sixth at national level ${ }^{22}$. The demographic trends of Hyderabad are given in Table 1 that shows the population picture over a hundred years.

Table 1 shows the demographic pattern of Hyderabad from the years 1901 to 2015. The unexpected growth can be seen in this table due to in-migration of people. The first master plan for Hyderabad was prepared in 1954 by the Town Planning Department, Government of Sindh (TPDGoS). The city has revealed itself in the form of impulsive residential development and other allied uses. In view of this situation and new delimitation of the control area of Hyderabad Development Authority (HDA), it is necessary to appraise the master plan from the years 2001-2015.

\subsection{Components and Architecture of CBDS}

The enormous data in Terabytes are difficult to manage, and required suitable software to store a massive amount of data efficiently. The data warehouse is a technique or a tool, which can be used to solve the problems of a larger quantity of data. With the help of data warehousing technique, terabytes of data can be stored efficiently. The features of data warehousing included historical data, improved database systems with larger quantity, provide analytical insights on the problems and easily interpretations by end users ${ }^{23}$. Data warehouses can store standardized data and provide easy predictions of subject matters. Data warehousing technique can really

Table 1. Hyderabad population trends

\begin{tabular}{crrcc}
\hline S.No & Year & Population & $\begin{array}{c}\text { Decade } \\
\text { wise Increase }\end{array}$ & $\begin{array}{c}\text { Increase/ } \\
\text { Decade }(\%)\end{array}$ \\
\hline 1. & 1901 & 69,178 & 0 & 0 \\
2. & 1911 & 75,952 & 6,774 & 9.79 \\
3. & 1921 & 813,838 & 5,886 & 7.75 \\
4. & 1931 & 101,699 & 19,861 & 24.26 \\
5. & 1941 & 127,500 & 25,801 & 25.37 \\
6. & 1951 & 229,211 & 101,711 & 79.77 \\
7. & 1961 & 434,860 & 205,649 & 89.72 \\
8. & 1971 & 636,198 & 201,338 & 46.30 \\
9. & 1981 & 751,000 & 114,802 & 18.04 \\
10. & 1991 & $1,050,000$ & 299,000 & 39.81 \\
11. & 2000 & $1,442,000$ & 392,000 & 37.33 \\
12. & 2010 & $1,882,000$ & 440,000 & - \\
13. & 2015 & $2,181,000$ & 299,000 & - \\
\hline
\end{tabular}

assist decision makers in their decisions and choosing of alternatives to problems. Hence, this technique could be utilized in this study, as the colossal amount of data can be stored for the concerned rural authorities, which could assist them in their decision making process. Data warehousing technique required database tools for data storage. There are many tools available, but the most popular are Teradata and Oracle. Teradata is preferred in this study, because it is purely designed for the data warehousing and provides many advantageous features, which are not available with the Oracle. So, by keeping in view the study's scope and limitations, Teradata and Visual Basics 6.0 were decided to be used in the design and development of this system. The former would be used at the back end and the latter would be used at the front end.

Teradata is a Relational Database Management System (RDBMS), which can store terabytes of data ${ }^{24}$ and can be easily connected with the computers of different specifications as shown in Figure 1.

Visual Basic (VB) is a powerful programming language, which was first launched in a year 1991 with its first version "Visual Basic 1.0". This is simply called a userfriendly programming language, which is mainly based on the concepts of visual tools and event driven coding ${ }^{25}$. Later on, Microsoft had also quickly launched VB-2 and 3. After the development of powerful latest versions of $\mathrm{VB}$, particularly with respect to database systems development, commercial companies started taking interest in this language. Immediately after this development, Rapid Application Development (RAD) was launched, which had put a positive impact on markets and assisted in commercial recognition of $\mathrm{VB}^{26}$.

Figure 2 shows the basic architecture of CBDS, in which planning database system takes the query and data as an input. Later on, the client's query is entertained and analyzed to display the query response.

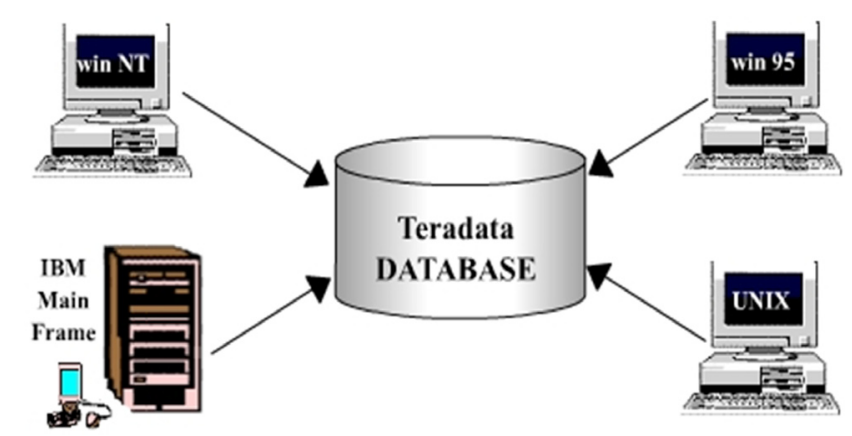

Figure 1. Typical teradata environment. 


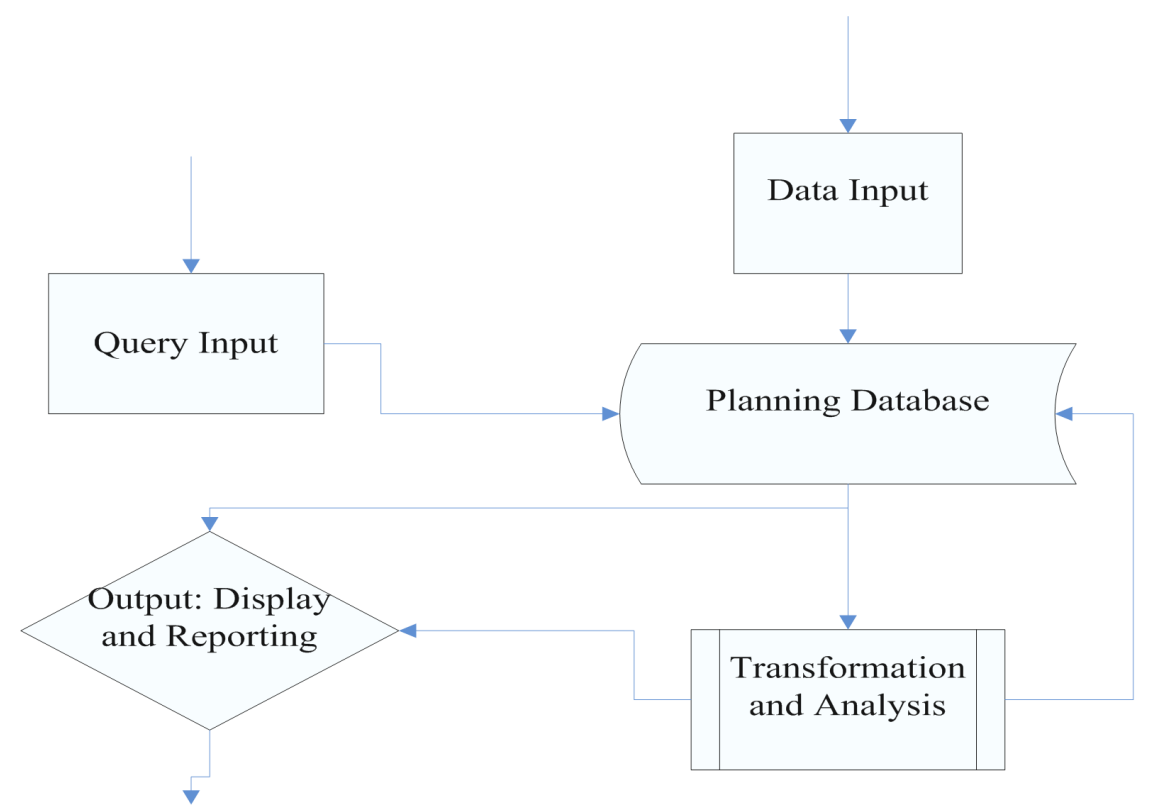

Figure 2. Architecture of CBDS

Keeping in view the client/server architecture, Figure 3 shows the basic architecture of the CBDS. As shown, the planning database is generated that takes data as an input. In addition, this database takes client's queries as an input and gives responses in the form of the results or answers to the client's queries. Client computers can interact with the Teradata servers with the help of Open Database Connectivity (ODBC). The process can be seen in Figure 3.
As shown in Figure 3, ODBC provided smooth connectivity between client and servers to procure required data from the databases.

\section{Results and Discussion}

The system has been designed and implemented after keeping in view the data, which has been used in "Hyderabad Master Plan 2001-2015", prepared by HDA.

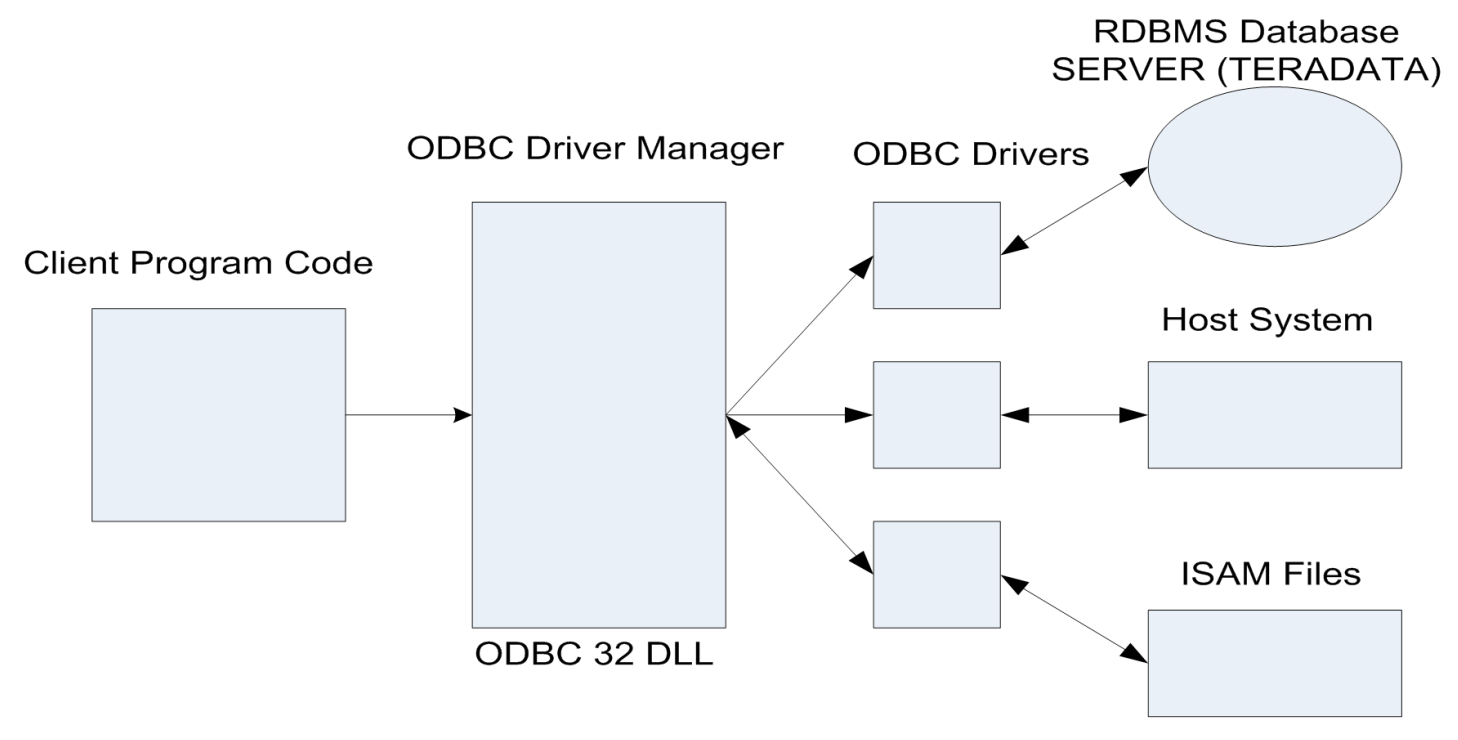

Figure 3. ODBC architecture. 
The description of user interfaces, which designed especially after taking the divergent fields used in the plan, is described afterwards.

\subsection{Breakup Areas}

In this display, information about the different land uses of a city is stored. The stored data included total area, occupied area, developed area and the vacant area. In Figure 4, results have been yielded after executing the query, in which the total scenario has been asked, i.e. "select all from breakup_areas". The data about the break-up areas are shown in the data grid and pie chart diagrams. The dissimilar color schemes exposed in the pie chart described divergent fields. For cantonment land use; a red color shows the total area of 2893 acres, green color illustrates the occupied area of 1800 acres, blue color informs about the developed area, and yellow color informed about the vacated area.

Figure 5 shows different fields that have been used in a table breakup_areas.

\begin{tabular}{|c|l|}
\hline \multicolumn{2}{|c|}{ breakup_areas } \\
\hline & \multicolumn{1}{|c|}{ ColumnName } \\
\hline 1 & s_no \\
\hline 2 & location \\
\hline 3 & Total_Area_Acres \\
\hline 4 & area_occ \\
\hline 5 & area_dev \\
\hline 6 & vac_area \\
\hline
\end{tabular}

Figure 5. Breakup areas (Fields).

\subsection{Existing Land use}

Figure 6 is about the current land use scenario of Hyderabad city. This explains the different existing land uses throughout the Hyderabad, including their total area in percentage. In this figure, the results have been capitulated after executing the query, in which only serial number was asked, i.e. "select s_no from current_land_ use". The result of the query can be shown in the data grid, and it is visible in three-dimensional line chart.

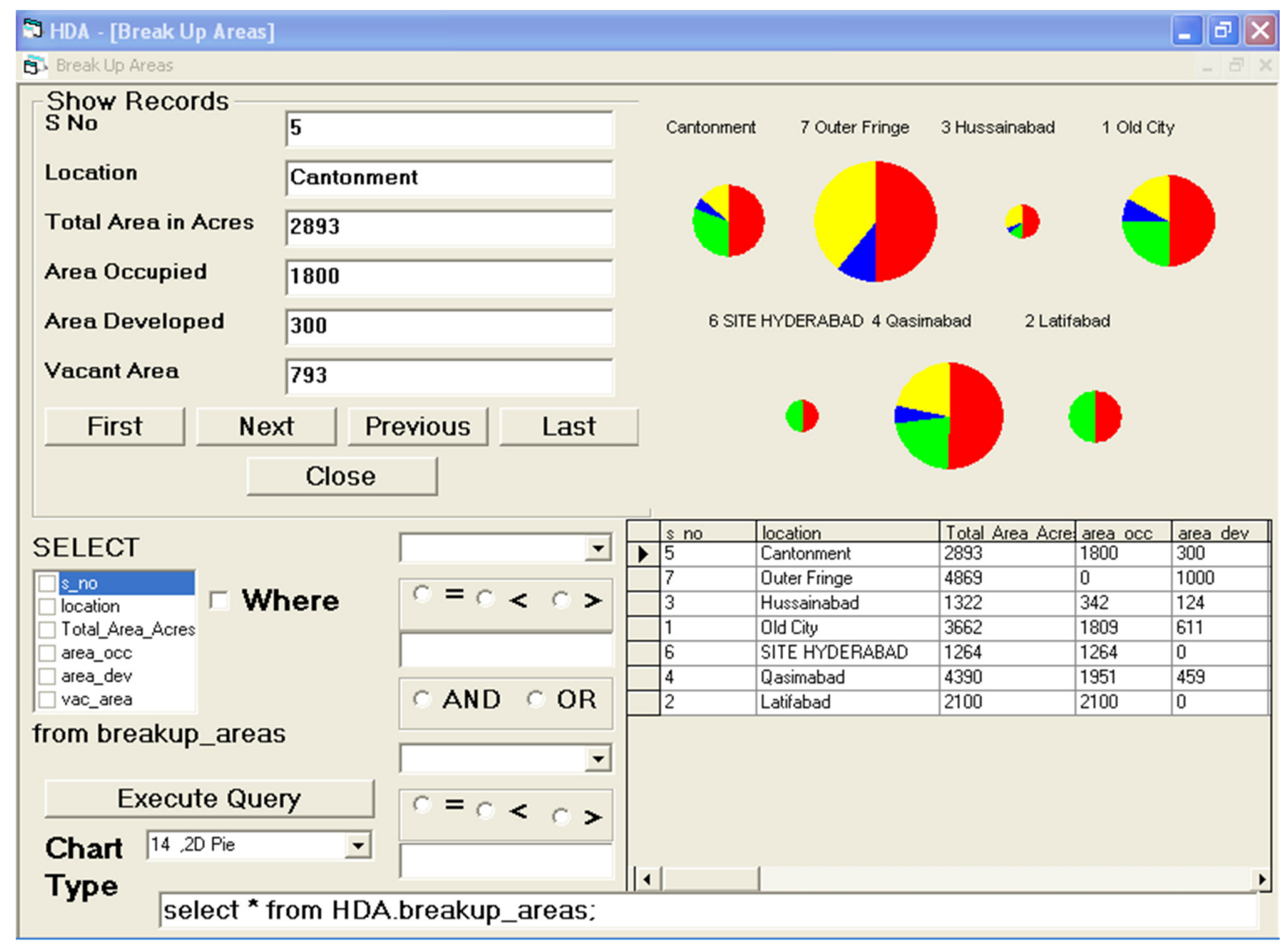

Figure 4. Breakup areas. 


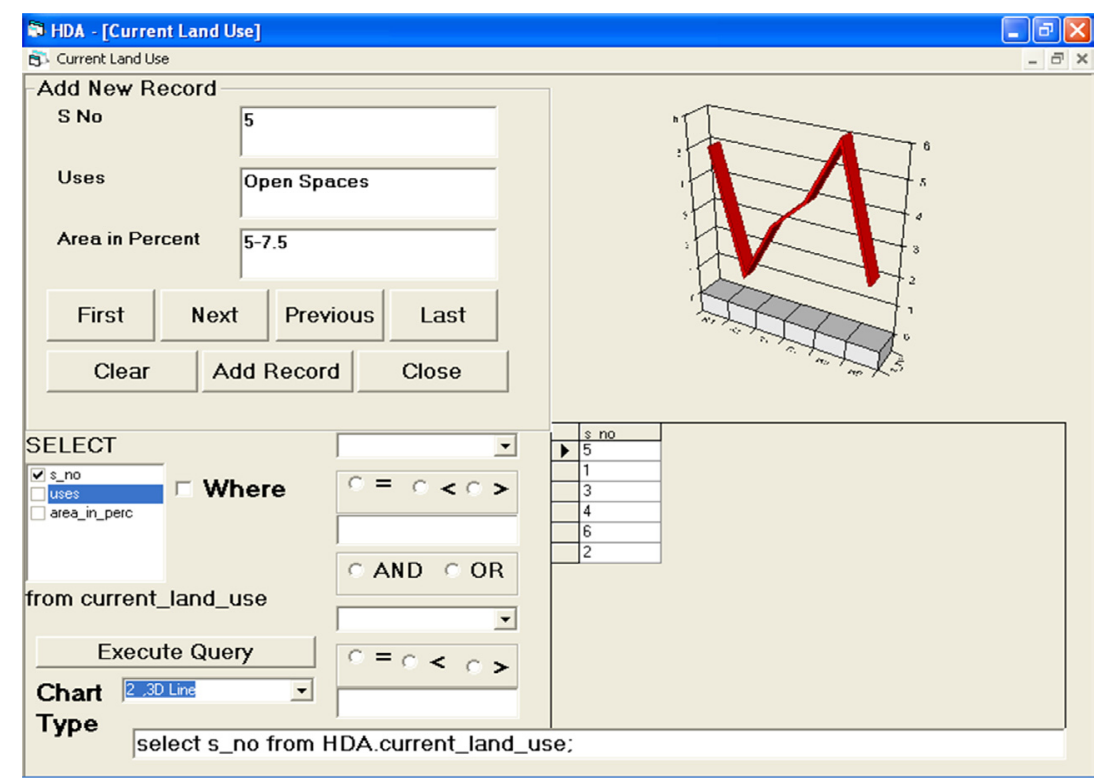

Figure 6. Existing land use.

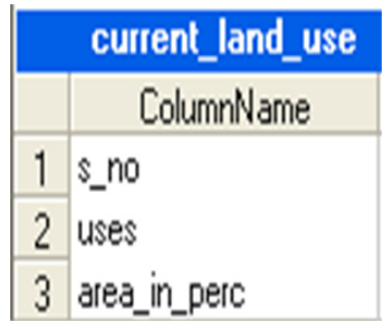

Figure 7. Existing land use (Fields).

Figure 7 illustrates information about the fields, which have been used in data, as taken from Hyderabad Master Plan 2001-15 about current_land_use. As in this case, three different fields like s_no, uses and area_in_perc are evident.

\subsection{Existing Recreation}

Figure 8 exemplifies the existing recreation facilities available in the Hyderabad. This elaborate the recreational areas of different prime locations throughout the Hyderabad city, including their total and an occupied area in acres. The data about the existing recreation is shown in the data grid and as well as it is represented in the twodimensional area chart diagram. In this Figure, the results have been yielded after executing the query, in which the location and the total area have been asked, i.e. "select location, Total_Area_Acres from Existing_recreation”.

Figure 9 shows diverse fields used in a table Existing recreation. In this case, only three fields have been come into account, i.e. s_no, location and Total_Area_Acres.

\subsection{Housing Needs}

Figure 10 shows the feature about Housing Need. This figure expresses the existing and projected population from the year 2001 to 2015, together with land requirements in acres for housing sector, and the total number of existing and required housing units. In this figure, the results have been yielded after executing the query, in which the total scenario has been asked, i.e. "select s_no, time_period, proj_pop, land_Reqd_acres, Houses_Reqd from Housing_Need". The data grid is screening the results, which have been captivating after executing the query and it can also be shown graphically in the two dimensional bar chart. The different color schemes exposed in the bar chart describe divergent fields, e.g. a red color shows the total population, green color illustrates the land requirements in acres and blue color informs about the housing needs.

Figure 11 elucidates different fields, which have been used in a table Housing_Need. The fields include s_no, time_period, proj_pop, land_Reqd_acres and Houses_ Reqd.

Figure 12 shows Housing_Need in different perspective. The result is represented graphically in three-dimensional combination chart.

\subsection{Housing Schemes}

Figure 13 is about different Housing Schemes developed by HDA. This mostly includes the names of the schemes, 


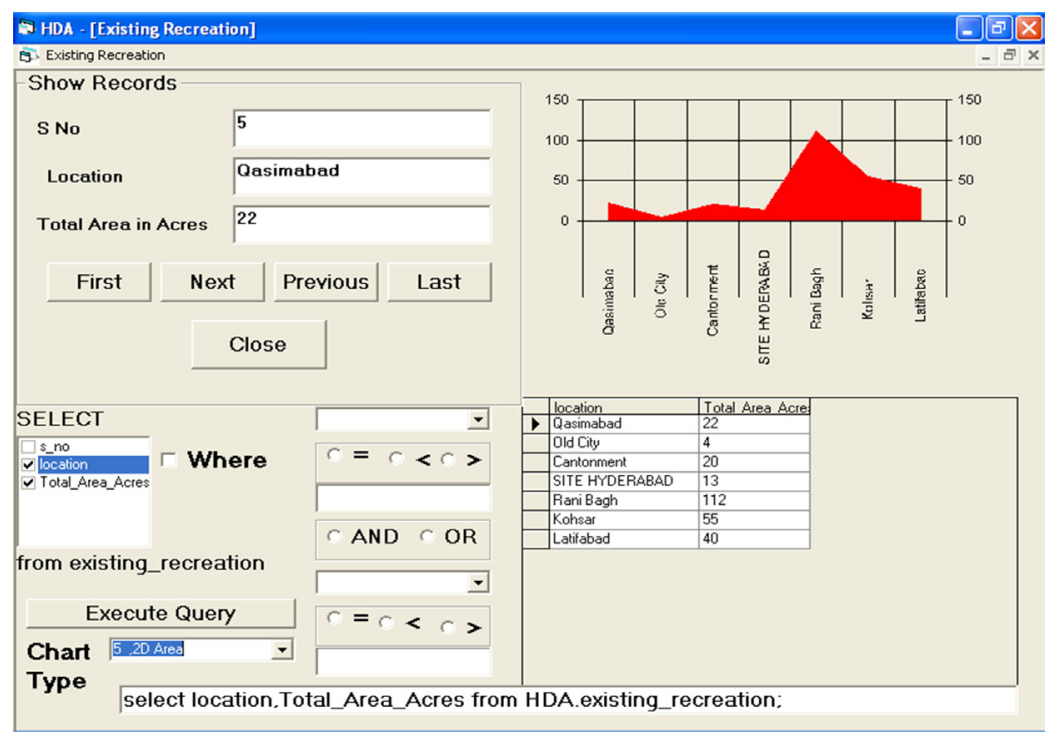

Figure 8. Existing recreation facilities.

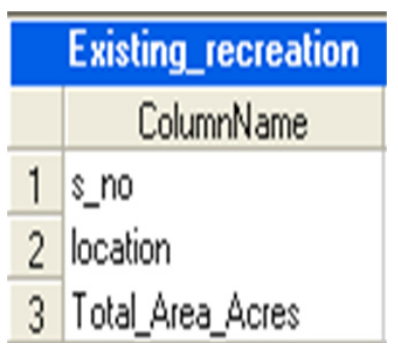

Figure 9. Existing recreation facilities (Fields).

a year in which that particular scheme developed along with their total population and housing units.

Figure 14 shows different fields, which have been used in a table Housing_Schemes.

\subsection{Open Spaces}

Figure 15 exemplifies the open_spaces. This figure defines the current situation about open spaces in a Hyderabad city together with the existing and the projected population, land required for open spaces and the number of open spaces needed according to the city's demographic characteristics. The data about open spaces are shown in a data grid and two-dimensional pie chart diagrams. In this figure, results have been yielded after executing a query, in which the serial number, year, a number of open spaces and land demand inquired, i.e. "select s_no, yer, number_ of_openspaces, land_demand from open_spaces”.

Figure 16 highlights different fields used in a table open_spaces. These fields included s_no, year, Population, no_of_openspaces and land_demand.

\subsection{Water Demand}

Figure 17 elaborates water_demand; this gives details about the population and water demand for the years 1998-2018. The data grid and three-dimensional combination diagram explain year wise population features and their water demand requirements. The results have been taken after executing a query in which population and its water demand have been asked. The query is "select all from water_demand". In a graphical representation, different color schemes have been used to explain the results; yellow color shows water demand, blue color highlights population, green color explains the years 1998 to 2018 and at last red one is about serial numbers.

Figure 18 informs about divergent fields, which have been used in a table water_demand.

The results are shown statistically and graphically, represented the data as stored in the CBDS. The prompt retrieval of data and its analysis could really assist different planning agencies and development authorities in formulating policies in time and support foster decisionmaking process.

It is expected that CBDS would play a revolutionary role, regarding data-storage facilities within the context of rural planning agencies and development authorities. The policy proposals can be developed easily now with the help of CBDS. The major rural problems, like rural inaccessibility, unavailability of transportation facilities could be mitigated with the timely implementation of transport policies, and growth could be prevailed all along deprived rural regions. 


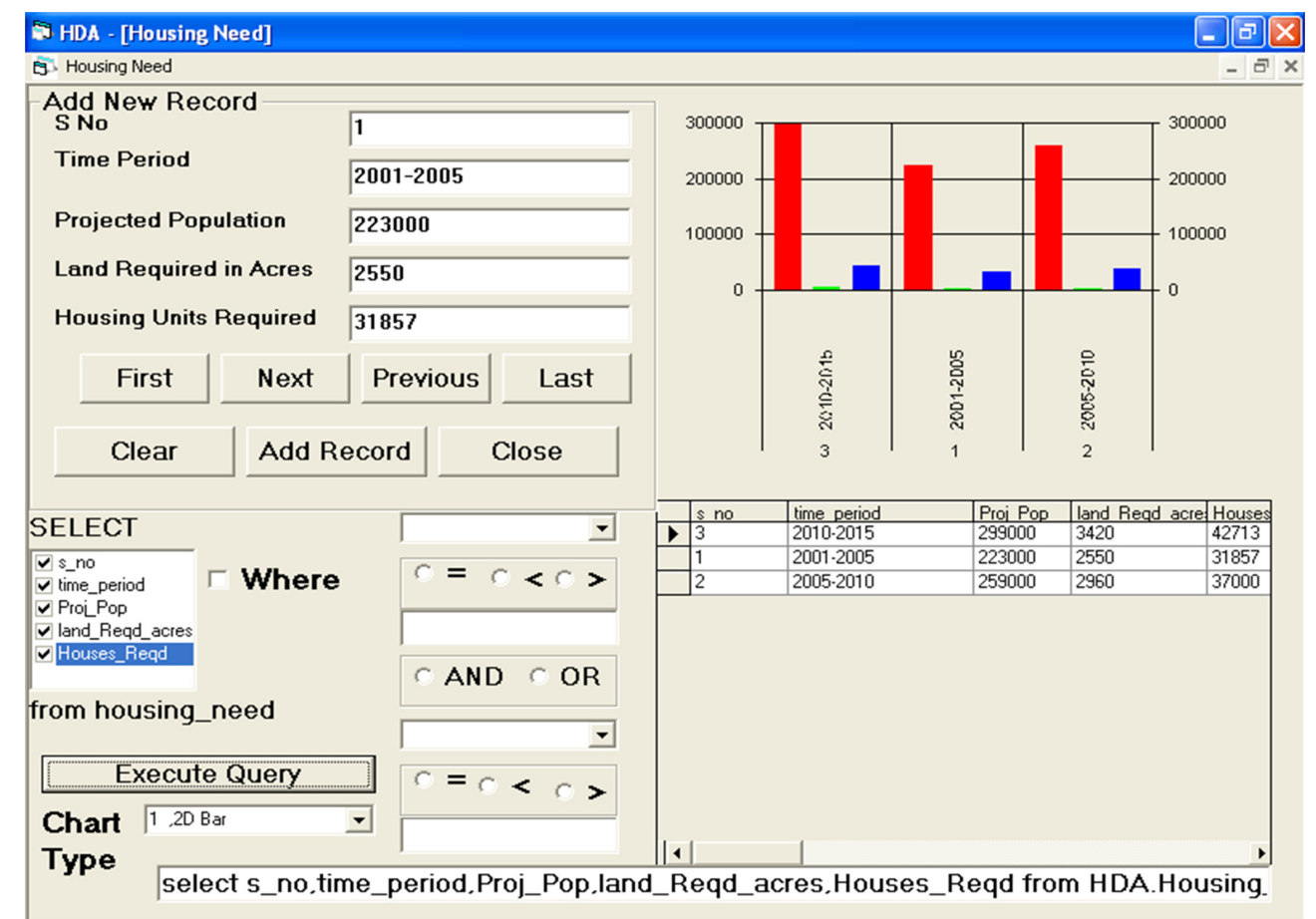

Figure 10. Housing needs.

\begin{tabular}{l|l|}
\hline & \multicolumn{1}{|c}{ housing_need } \\
\hline 1 & \multicolumn{1}{|c}{ ColumnName } \\
\hline 2 & time_period \\
\hline 3 & Proi_Pop \\
\hline 4 & land_Reqd_acres \\
\hline 5 & Houses_Reqd \\
\hline
\end{tabular}

Figure 11. Housing needs (Fields).

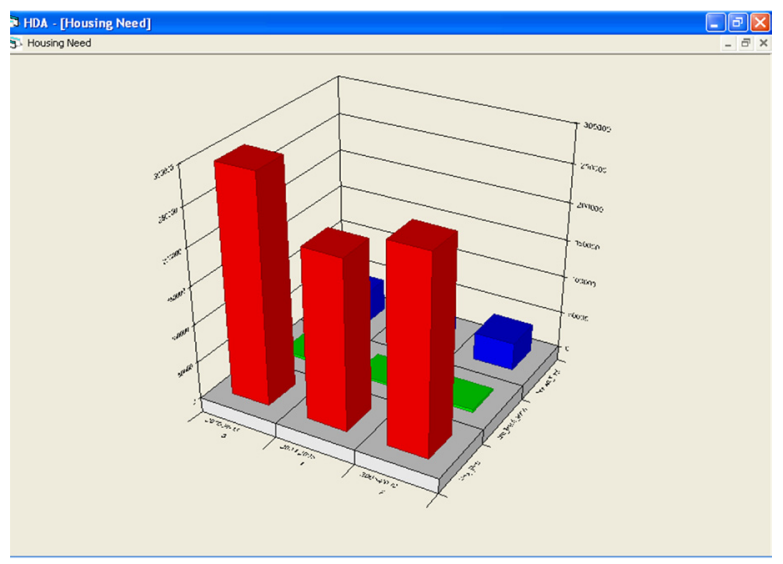

Figure 12. Housing needs.

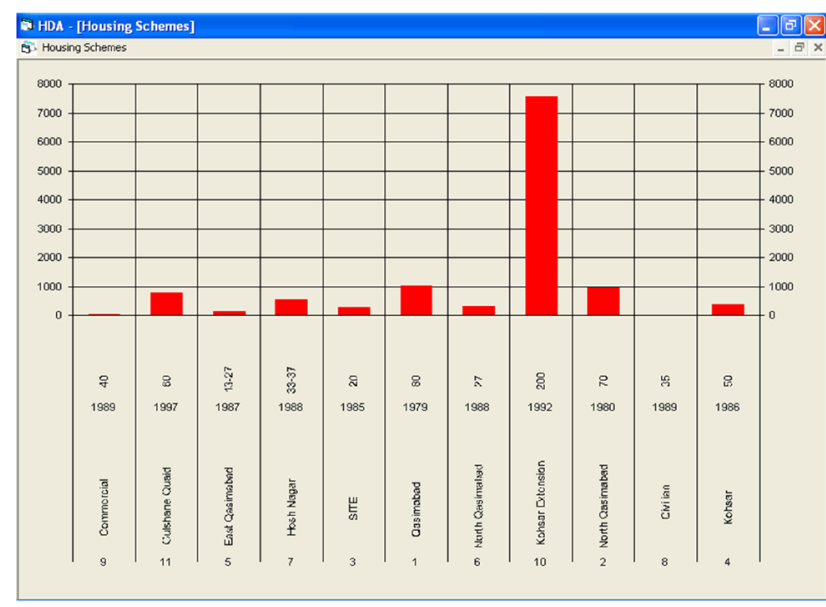

Figure 13. Housing schemes.

\begin{tabular}{|l|l|}
\hline & \multicolumn{1}{|c|}{ housing_schemes } \\
\hline & \multicolumn{1}{|c|}{ ColumnName } \\
\hline 1 & s_no \\
\hline 2 & Starting_Date \\
\hline 3 & Total_Plots \\
\hline 4 & Area \\
\hline 5 & Scheme_name \\
\hline
\end{tabular}

Figure 14. Housing schemes (Fields). 


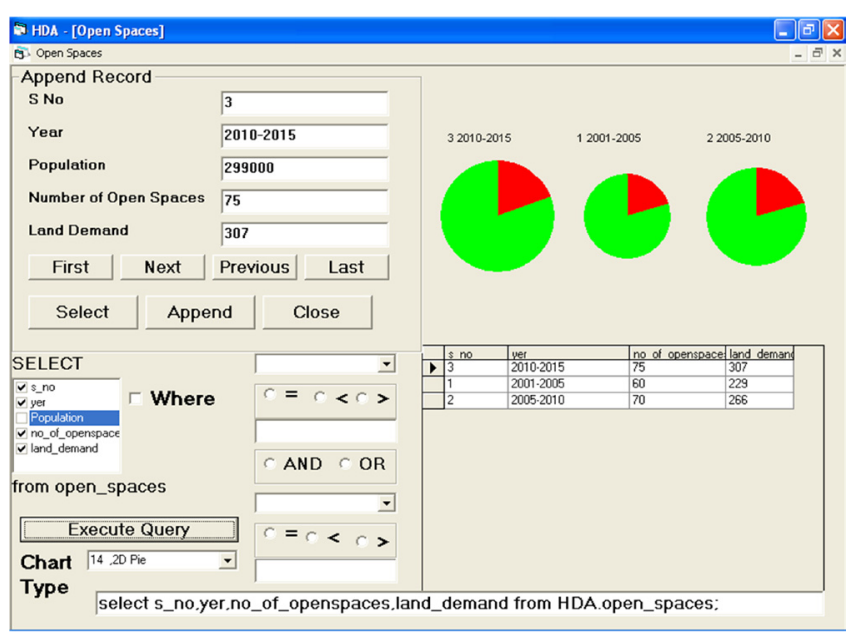

Figure 15. Open spaces.

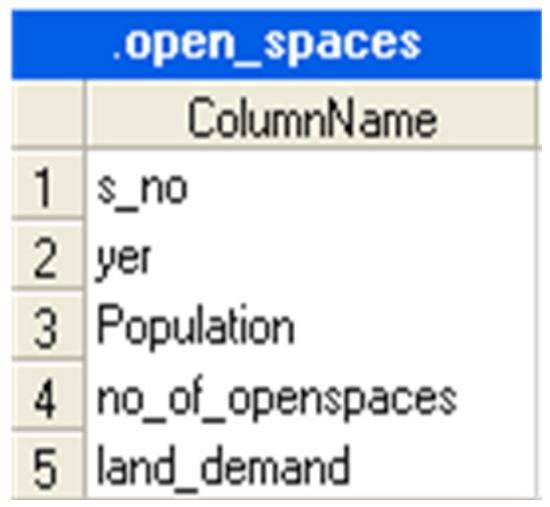

Figure 16. Open spaces (Fields).

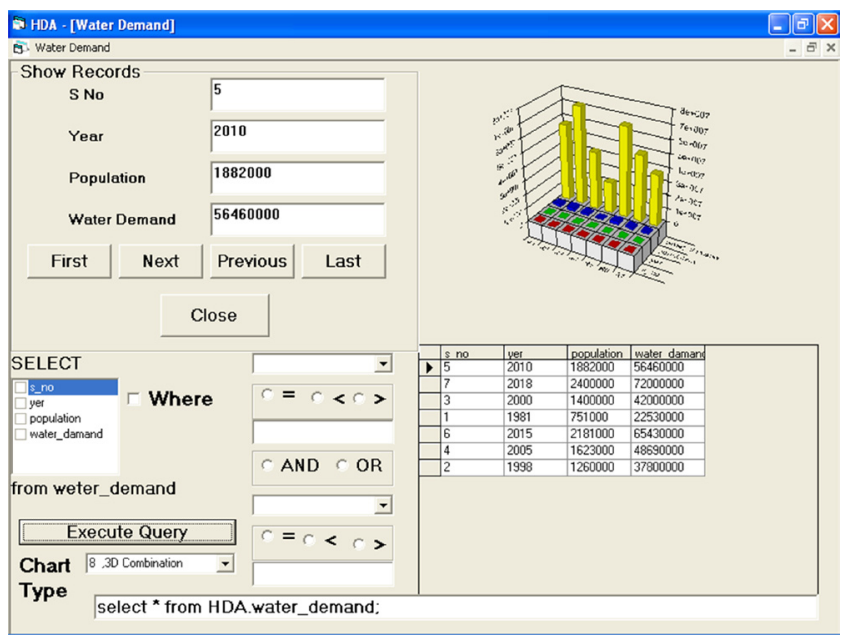

Figure 17. Water demand.

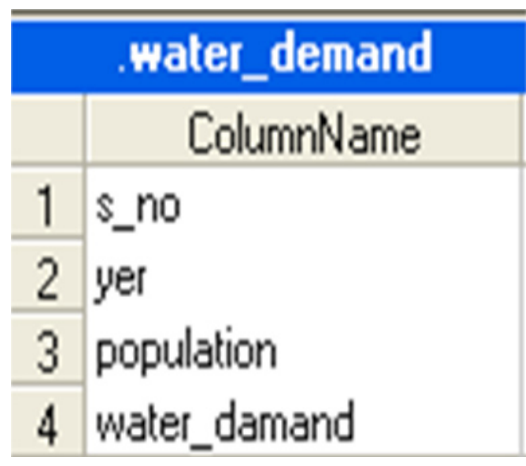

Figure 18. Water demand (Fields).

\section{Conclusion}

In a rural environment, inaccessibility can be considered as a major determinant responsible for the rural-regional deprivation. There could be many reasons for that, but the most triggering issue can be the absence of policy proposals. Rural development authorities or planning agencies are responsible for the development of transport policies to resolve the transport-related issues of the local population. Transport policies can be formulated with the availability of data and its easy retrieval. It was found that rural planning agencies of developing countries were struggling to manage data-related issues. Henceforth, CBDS was developed, which can easily manage the gigantic data effortlessly. The run-time snaps of the system verified its reliability and working. This system is dynamic in nature and can be implemented to resolve the data management issues of various public and private organizations. The policy plans can be developed now with the easy retrieval of data, which was one of the issues of the local planning agencies. CBDS can be said a remarkable achievement with respect to rural accessibility problems, which could bring prosperity and affluence with the execution of policy proposals in time.

\section{Acknowledgement}

The authors are thankful to the Department of City and Regional Planning for their support and provision of a suitable research environment.

\section{References}

1. Banister D, Berechman Y. Transport investment and the promotion of economic growth. J Transport Geogr. 2001; 9(3):209-18. 
2. Bank AD. Sub Regional Transport connectivity Sector Project in Pakistan. 2005.

3. Arcury TA, Preisser JS, Gesler WM, Powers JM. Access to Transportation and Health Care Utilization in a Rural Region. J Rural Health. 2005; 21(1):31-8.

4. Carrasco J-A, Miller EJ. The social dimension in action: A multilevel, personal networks model of social activity frequency between individuals. Transport Res Pol Pract. 2009; 43(1):90-104.

5. Farrington J, Farrington C. Rural accessibility, social inclusion and social justice: towards conceptualisation. J Transport Geogr. 2005; 13(1):1-12.

6. Talpur MAH, Napiah M, Chandio IA, Memon IA. Analyzing Public Sector Education Facilities: A Step Further Towards Accessible Basic Education Institutions in Destitute Subregions. Int Educ Stud. 2014; 7(4):110-9.

7. Handy S. Regional transportation planning in the US: An examination of changes in technical aspects of the planning process in response to changing goals. Transport Pol. 2008; 15(2):113-26.

8. Winkler D, Hatfield R. The Devolution Plan in Pakistan. The World Bank; 2002 May. 25 p.

9. The Improvement of Developing Country Transport Data Collection, Analysis and Dissemination; Background Paper CSD18/2010/BP11. 2010. UNDESA; 2010 May 3-14. 6 p.

10. Chiang RHL. A knowledge-based system for performing reverse engineering of relational databases. Decis Support Syst. 1995; 13(3-4):295-312.

11. Vanthienen J, Wets G. Integration of the decision table formalism with a relational database environment. Inform Syst. 1995; 20(7):595-616.

12. Ahmed S. Does Economic Geography Matter for Pakistan? A Spatial Exploratory Analysis of Income and Education Inequalities. 27th PIDE-PSDE Annual Conference, (MPRA); 2011 Dec; Munich, Germany. Munich Personal RePEc Archive Paper No 35062; 2011.1-33.

13. Masood MT, Khan A, Naqvi HA. Transportation Problems in Developing Countries Pakistan: A Case-in-Point. Int J Bus Manag. 2011; 6 (11):256-66.
14. Ali SS, Tahir S. Dynamics of Growth, Poverty, and Inequality in Pakistan. Pakistan Dev Rev. 1999; 38(4):837-58.

15. Khan A, Saboor A, Mian SA, Malik IA. Approximation of Multidimensional Poverty across Regions in Pakistan. Eur J Soc Sci. 2011; 24(2):226-36.

16. Naeem A. Sindh's Imbalanced Urbanization: Seeking Sustenance through Revival of Historic Urban Centres. J Sustain Dev. 2011; 4(5);94-107.

17. World Development Indicators-2012. 1818-H Street NW, Washington, D.C. 20433 USA: The World Bank; 2012.

18. Talpur MAH, Napiah M, Chandio IA, Khahro SH. Transportation Planning Survey Methodologies for the ProposedStudyofPhysicalandSocio-economicDevelopment of Deprived Rural Regions: A Review. Mod Appl Sci. 2012; 06(07):1-16.

19. Greater Hyderabad Master Plan (2001-2015). In: Planning and Development Section HDA. Hyderabad: 2001.

20. Bhatti AK. Town Planning for the Third World. Lahore, Pakistan: Feroze sons; 1991.

21. Rangwala SC. Town Planning. Charotar Publishing House Pvt. Limited; 2009.

22. Akhtar S, Dhanani MR. City-Size Distribution In Pakistan. Sindh University Research Journal (Science Series). 2012; 44(4):699-702.

23. Arun S, Atish PS. Toward Developing Data Warehousing Process Standards: An Ontology-Based Review of Existing Methodologies. IEEE Trans Syst Man Cybern C Appl Rev. 2007; 37(1):17-31.

24. Cooper G, Raymer M, Doom T, Krane D, Futamura N. Indexing genomic databases. Fourth IEEE Symposium on Bioinformatics and Bioengineering, 2004 BIBE 2004 Proceedings. IEEE; 2004 May 19-21.

25. Clark D. Visual Basic and the future of Web-application development. Computer. 2001; 34(8):16-8.

26. Perry G. Sams Teach Yourself Visual Basic 6 in 24 Hours. Pearson Education Inc; 1998. 